\title{
High-Temperature Spectroscopy for Nuclear Waste Applications
}

\author{
P.M. Grant \\ P. Robouch \\ R.A. Torres \\ R.J. Silva
}

This paper was prepared for the

Methods and Applications of Radioanalytical Chemistry II

Kona, HII

April 21-27, 1991

Manuscript Date: September 1991

Publication Date: October 1991

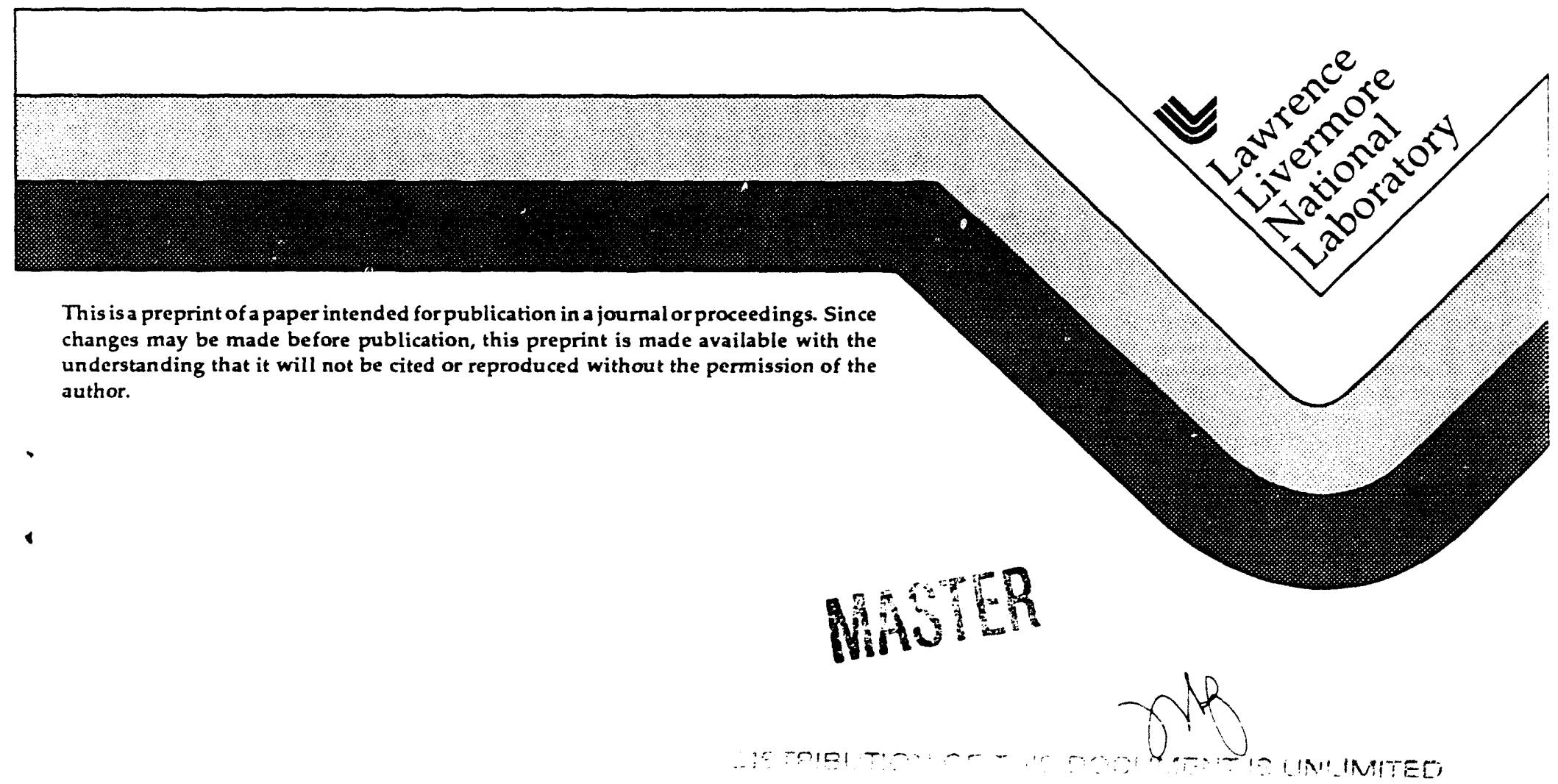




\section{DISCI.AIMER}

This document was prepared as an account of work sponsored by an agency of the United States Government. Neither the United States Government nor the University of California nor any of their employees, makes any warranty, express or implied, or assumes any kegal liability or responsibility for the accuracy. completeness, or usefulness of any informatiog. apparatus, product, or process disclosed. or represents that its use wmald not infringe privately owned rights. Reference herein to any specific commercial products. process, or service by trade name, trademark, manufacturer, or otherwise. does not necessarily constitute or imply its endorsement. recommendation. or favoring by the United Siates Government or the University of California. The views and opinions of authors expressed herein do not necessarily state or reflect those of the United States Goverament or the University of California. and shall not be used for advertising or product endorsement purposes. 
HIGH-TEMPERATURE SPECTROSCOPY FOR NUCLEAR WASTE APPLCATIONS

\author{
P.M. Grant, P. Robouch, R.A. Torres, \& R.J. Silva \\ Nuclear Chemistry Division L-234 \\ Lawrence Livermore National Laboratory \\ Livermore, CA 94550 \\ UCRL-JC--106028 \\ DE 92002167
}

Instrumentation has been developed to perform uv-vis-nir absorbance measurements remotely and at elevated temperatures and pressures. Fiber-optic spectroscopy permits the interrogation of radioactive species within a glovebox enclosure at temperatures ranging from ambient to $>100^{\circ} \mathrm{C}$. Spectral shifts as a function of metal-ligand coordination are used to compute thermodynamic free energies of reaction by matrix regression analysis. $\mathrm{Pr}^{3+}$ serves as a convenient analog for trivalent actinides without attendant radioactivity hazards, and recent results obtained from $20^{\circ}-95^{\circ} \mathrm{C}$ with the $\mathrm{Pr}$-acetate complexation system are presented. Preliminary experimentation on Am(III) hydrolysis is also described.

\title{
INTRODUCTION
}

The present strategy for the underground burial of high level nuclear wastes in a geologic repository depends upon safeguards against radionuclide migration into the biosphere for up to 10,000 years after site closure. ${ }^{1}$ This large extrapolation in time requires that geochemical modeling play a central role in the assessment of waste isolation, and theoretical efforts for this purpose are active areas of current research. $^{2}$

Modeling software requires thermodynamic data relevant to interactions of actinides and other radioisotopes with groundwater and various geologic media. Although much data exist ${ }^{3}$ for chemical interactions around $25^{\circ} \mathrm{C}$, the same is not true for systems at the elevated temperatures expected in the near-field vicinity of a nuclear repository. Knowledge of important reaction parameters of aqueous 
systems in the $50-150^{\circ} \mathrm{C}$ regime is imperative for reliable prediction of potential waste migration under pragmatic scenarios. Although calculations based on lowertemperature data can be used to estimate high-temperature thermochemical properties, ${ }^{4}$ experimental measurement of equilibrium constants and enthalpies at elevated temperatures should provide more accurate data for input to modeling codes.

We have developed apparatus to perform optical spectroscopy at $20-125^{\circ} \mathrm{C}$ within the regulated enclosure of a radioactivity glovebox. Measurements are effected remotely with fiber-optic probes, and sample tomperature is regulated with a dry-block heater. Metal-ligand stability constants (free energies of reaction) can be computed from changes in wavelength and absorbance as the degree of metal complexation is varied. ${ }^{5}$

We report stability-constant measurements for the praseodymium-acetate ( $\mathrm{Pr}$ ac) system at temperatures of $20,50,65,80$, and $95^{\circ} \mathrm{C}$. The $\mathrm{Pr}^{3+}$ cation is a useful analog for trivalent actinide species without the accompanying radiation hazard. ${ }^{6}$ Initial experimentation on $\mathrm{Am}^{3+}$ hydrolysis was also performed with the hightemperature spectroscopy (HiT-SPEC) instrumentation.

\section{EXPERIMENTAL}

For the Pr-ac experiments, solutions with varying ligand-to-metal (L/M) ratios were synthesized from $\mathrm{Pr}_{6} \mathrm{O}_{11}$, acetic acid, and $\mathrm{HClO}_{4}$. The inert salt $\mathrm{NaClO}_{4}$ was used to adjust each individual solution to a total ionic strength $I=1.00 \mathrm{M}$. All reagents were of analytical reagent-grade quality or better, and details of solution preparation and characterization are presented elsewhere. ${ }^{7}$ The $\mathrm{Pr}$-ac solutions had compositions of approximately $[\mathrm{Pr}]_{\mathrm{t}}=19 \mathrm{mM}, 0 \leq[\mathrm{ac}]_{\mathrm{t}} \leq 400 \mathrm{mM}, \mathrm{p}[\mathrm{H}]=4.4$ 4.7 , and $\mathrm{I}=1.00 \mathrm{M}\left(\mathrm{NaClO}_{4}\right)$. The solutions for the study of $\mathrm{Am}$ (III) hydrolysis were $\left[{ }^{243} \mathrm{Am}\right]=10^{-4} \mathrm{M}, \mathrm{p}[\mathrm{H}]=4.8-6.7$, and $\mathrm{I}=0.50 \mathrm{M}\left(\mathrm{NaClO}_{4}\right)$.

The core of the HIT-SPEC instrumentation is a Guided Wave model 200 fiberoptic spectrometer. ${ }^{8,9}$ Absorption measurements on the $\mathrm{Pr}$-ac solutions were made over $415-515 \mathrm{~nm}$ in $0.05-\mathrm{nm}$ intervals, and between $490-530 \mathrm{~nm}(\times 0.05 \mathrm{~nm})$ for the Am(III)-hydrolysis experiments. Temperature regulation of a solution was 
effected with a modified Techne model DB-1 Dri-Block heater, and, for the Pr-ac absorbance data, setpoints of $t=(20 \pm 0.6),(50 \pm 0.5),(65 \pm 0.5),(80 \pm 0.6)$, and $(95 \pm 0.5)^{\circ} \mathrm{C}$ were maintained. A thorough description of the instrumentation and spectral data-acquisition procedure can be found elsewhere. ${ }^{10}$

\section{DATA ANALYSIS}

Guided Wave data files were processed on an IBM PS/2. Spectra Calc software (Galactic Industries Corp.) was used for background subtraction and baseline normalization. For the $\mathrm{Pr}$-ac experiments, data spanning the $\mathrm{Pr}^{3+}{ }^{3} \mathrm{H}_{4} \rightarrow{ }^{3} \mathrm{P}_{0}$ transition at $482 \mathrm{~nm}$ were analyzed by the program SQUAD ${ }^{11}$ for each studied temperature; for Am(III)-hydrolysis, the absorption peak at $503 \mathrm{~nm}$ was utilized.

SQUAD employs matrix regression analysis to calculate multiparameter values (overall formation constants $\beta_{i}$ and corresponding extinction coefficients $\varepsilon_{i, \lambda}$ at each input $\lambda$ ) by solving mass-balance equations and fitting the measured absorbance data. In the present Pr-ac experimental system, two metal-ligand complexes and one acid species have been previously observed at $25^{\circ} \mathrm{C} .^{3}$ For each individual analytic solution, therefore, the total metal concentration, $M_{t}$, is given by ${ }^{12}$

$$
M_{t}=\sum_{i=0}^{2}\left[M L_{l}\right]=[M]\left(1+\sum_{i=1}^{2} \beta_{10 /}[L]^{\prime}\right)
$$

Similarly, the total acetate concentration, $L_{T}$, is expressed by

$$
\begin{aligned}
L_{t} & =\sum_{j=0}^{1}[H, L]+\sum_{i=0}^{2} i\left[M L_{l}\right] \\
& =[L]\left(1+\beta_{011}\left[H^{+}\right]\right)+M_{t} \cdot\left(\frac{\sum_{i=1}^{2} i \beta_{101}[L]^{\prime}}{1+\sum_{i=1}^{2} \beta_{101}[L]^{\prime}}\right) \\
& =[L]\left(1+\beta_{011}\left[H^{+}\right]\right)+M_{t} \cdot \bar{n}_{L}
\end{aligned}
$$

where $\beta_{011}$ is the protonation constant of acetic acid and $\bar{n}_{L}$ is the average ligand number. [The subscript triple-indices refer to the number of atoms of metal, hydrogen, and ligand, respectively, in the complex. Thus, "Oi1" indicates the 
reaction $i H+L=H_{i} L, " 10 j "$ indicates $M+j L=M L_{j}$, etc.] The measured total absorption at a given $\lambda, A_{t, \lambda}$, is described by Beer's Law

$$
A_{t, d}=1 \sum_{i=0}^{2} e_{(\lambda, 1)}\left[M L_{1}\right]
$$

where $l$ is the optical path length.

SQUAD arrives at a final result through an iterative procedure that entails initial estimates of the $\beta_{i}$. It first calculates free-ligand concentration $[L]$ and then all other species concentrations $\left[M L_{1}\right]$. With these data, a linear regression fit to $A_{t, \lambda}$ in equation (3) gives best values of all of the extinction coefficients at a chosen $\lambda$. A calculated total absorbance, $A_{t, \text { calc }}$ is then compared with the measured value to compute an unweighted sum-of-squares. The full comparison is actually a double summation over all solutions, $x$, and over all incorporated wavelengths, $\lambda$ :

$$
U^{2}=\Sigma_{\lambda}\left(\Sigma_{x}\left[A_{t, \text { axac }}-A_{\text {t,expor. }}\right]^{2}\right)
$$

This computation is then repeated with new values of $\beta_{i}$ until $U^{2}$ is minimized and the convergence criterion is satisfied.

Only the metal stability constants were permitted variation in these analyses. Acid constants were fixed at values determined by interpolation of high-temperature potentiometric data measured by MESMER et al. ${ }^{13}$ As discussed in detail elsewhere, ${ }^{10}$ the measurement of $\mathrm{p}[\mathrm{H}]$ at elevated temperatures was avoided by treating the total hydrogen inventory $\left(H_{t}\right)$ of each solution as a conserved quantity and allowing $\left[\mathrm{H}^{+}\right]$to vary as a free parameter, analogous to a second metal species in solution.

\section{RESULTS AND DISCUSSION}

In the Pr-ac experiments, at any given temperature the absorption spectra displayed increasing redshift with increasing $L / M$. This behaviour has been previously observed in other studies with $\mathrm{Pr}$ at room temperature. ${ }^{7,14}$ For the Am(III)-OH series, increasing hydrolysis was manifest as decreasing absorbance in the 503-nm peak. 
Experimental results for the first two Pr-ac stability constants are presented in Table 1, and these data are corrected for the thermal expansivity of aqueous solutions. All equilibrium-constant uncertainties listed in this work are $1 \sigma$ values and are the errors reported by SQUAD. ${ }^{11}$ They are thus minimum values associated with this work, as no attempt was made to propagate uncertainties inherent in solution syntheses, $\mathrm{p}[\mathrm{H}]$ assays, etc. However, the latter errors are unquestionably small compared to those inherent in the optical data and regression analyses.

\begin{tabular}{|c|c|c||}
\hline \multicolumn{3}{|c|}{$\begin{array}{c}\text { Table 1. Overall stability constants at } \mathrm{I}=1.0 \mathrm{M} \\
\text { for the system: } \operatorname{Pr}_{1-1}+L=\mathrm{PrL}_{i} \\
\text { for } \mathrm{i}=1-2 \text { and } L=\text { acetate. }\end{array}$} \\
\hline \hline$t\left({ }^{\circ} \mathrm{C}\right)$ & $\beta_{101}$ & $\beta_{102}$ \\
\hline 20 & $63 \pm 4$ & $350 \pm 50$ \\
\hline 50 & $54 \pm 6$ & $330 \pm 70$ \\
\hline 65 & $47 \pm 5$ & $490 \pm 90$ \\
\hline 80 & $57 \pm 7$ & $610 \pm 100$ \\
\hline 95 & $62 \pm 4$ & $300 \pm 50$ \\
\hline
\end{tabular}

Comparison of the results of this work at $20^{\circ} \mathrm{C}$ with $25^{\circ} \mathrm{C}$-data measured by potentiometry, ${ }^{7,15}$ visible spectroscopy, ${ }^{7}$ and laser-induced photoacoustic spectroscopy ${ }^{7}$ is possible. The Pr-ac HiT-SPEC results for both $\beta_{101}$ and $\beta_{102}$ are in very good agreement with the existing literature.

The Am(III)-hydrolysis investigation was hindered by a lack of $p[H]$ control. The $\mathrm{p}[\mathrm{H}]$ stability of several of the analytic solutions was but marginally acceptable, 
and the results of this study can only be considered preliminary or semi-quantitative at best. Nevertheless, the SQUAD result for the first hydrolysis constant at $22^{\circ} \mathrm{C}$ was $\log K_{1-10}=-7.5 \pm 0.6$. The expected value computed from NEA-selected data and Specific-Ion Interaction Theory is -7.12 at $\mathrm{I}=0.5 \mathrm{M}^{16}$ These experiments will be repeated with suitably-buffered Am(III) solutions in the near future.

\section{ACKNOWLEDGEMENTS}

Prepared by Yucca Mountain Site-Characterization Project (YMP) participants as part of the Civilian Radioactive Waste Management Program. The YMP is managed by the Yucca Mountain Site-Characterization Project Office of the U.S. Department of Energy, Las Vegas, Nevada.

This work was performed under the auspices of the U.S. Department of Energy by Lawrence Livermore National Laboratory under Contract W-7405-ENG48.

This paper is dedicated to the memory of Dr. D.F. Patrick Grant for a lifetime of devoted service to family and community health care. 


\section{REFERENCES}

1. J.E. Campbell, R.M. Cranwell, Science, 239 (1988) 1389.

2. D.C. Melchior, R.L. Bassett, eds., Chemical Modeling of Aqueous Systems II, ACS Symposium Series 416, American Chemical Society, Washington D.C., 1989.

3. A.E. Martell, R.M. Smith, Critical Stability Constants, 6 vols., Plenum Press, New York, 1974-1989.

4. S.L. Phillips, L.F. Silvester, High Temp.- High Press., 16 (1984) 81.

5. F.R. Hartley, C. Burgess, R.M. Alcock, Solution Equilibria, Ellis Horwood, Chichester, 1980, chapter 8.

6. J.J. Katz, G.T. Seaborg, L.R. Morss, eds., The Chemistry of the Actinide Elements, 2nd ed., 2 vols., Chapman \& Hall, London, 1986.

7. R.A. Torres, C.E.A. Palmer, P.A. Baisden, R.E. Russo, R.J. Silva, Anal. Chem., 62 (1990) 298.

8. P. Fitch, A.G. Gargus, Amer. Lab., 17[12] (1985) 64.

9. R.E. Schirmer, A.G. Gargus, Amer. Lab., 18[12] (1986) 30.

10. P.M. Grant, P. Robouch, R.A. Torres, P. Baisden, R.J. Silva, J. Soln. Chem., in press.

11. D.J. Leggett, ed., Computational Methods for the Determination of Formation Constants, Plenum Press, New York, 1985, pp. 159-220.

12. H. Rossotti, The Study of Ionic Equilibria, Longman, London, 1978, pp. 67-77.

13. R.E. Mesmer, C.S. Patterson, R.H. Busey, H.F. Holmes, J. Phys. Chem., 93 (1989) 7483.

14. N.K. Davidenko, A.G. Goryushko, K.B. Yatsimirskii, Russ. J. Inorg. Chem., 18 (1973) 943.

15. A. Sonesson, Acta Chem. Scand., 12 (1958) 1937.

16. R. Silva, G. Bidoglio, M.H. Rand, Chemical Thermodynamics of Americium, Nuclear Energy Agency, Paris, April 1990 (draft). 

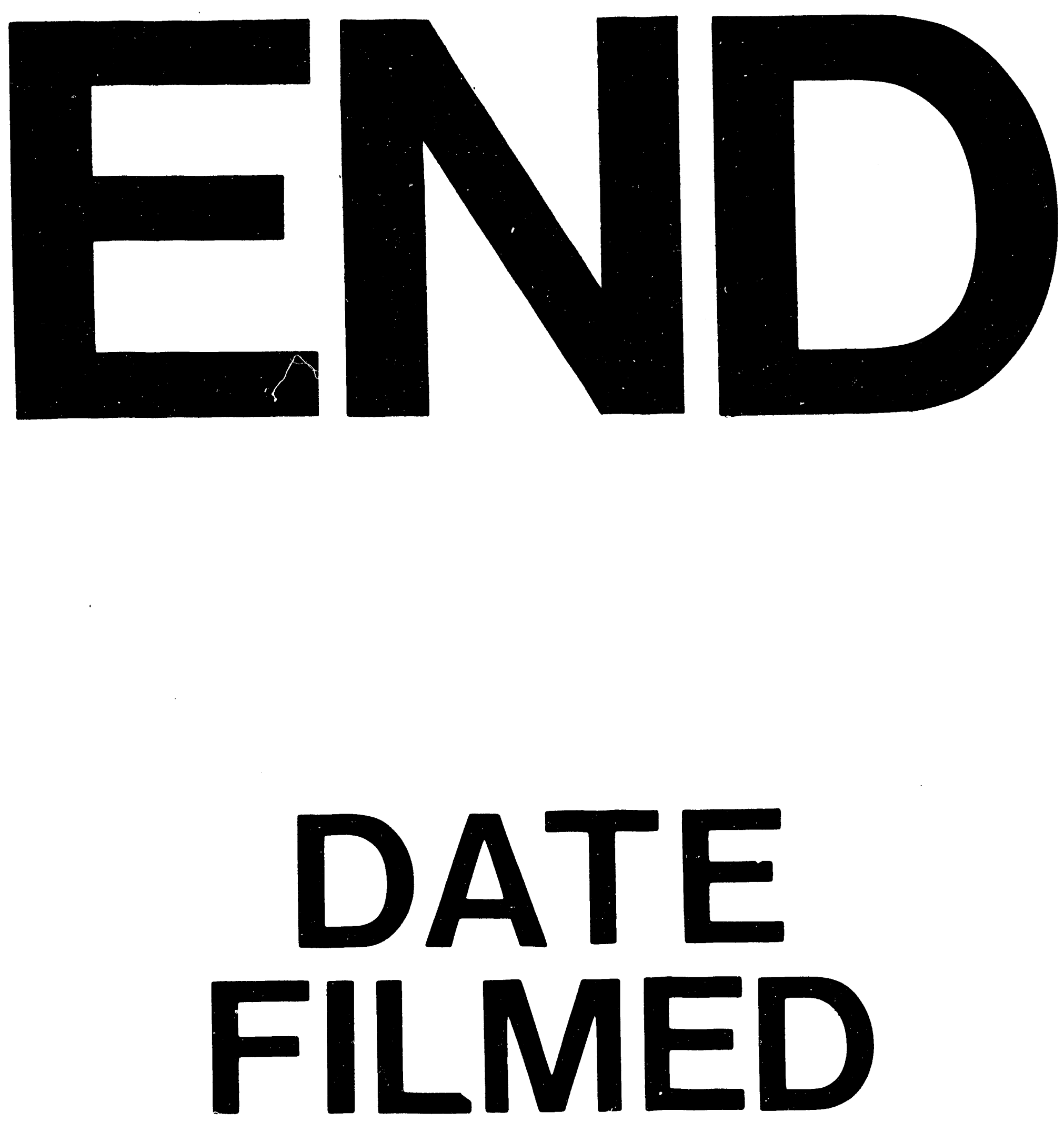

I

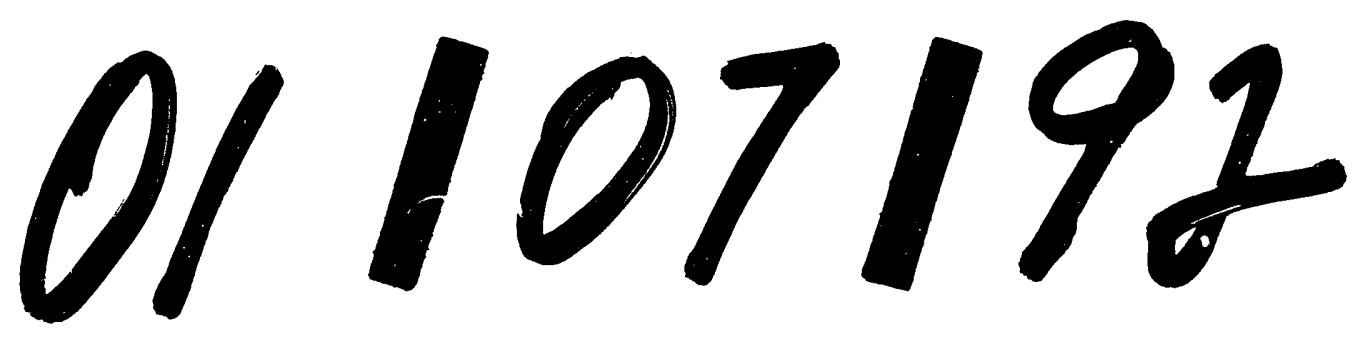


